Research Article

\title{
Free Vibrations and Nonlinear Responses for a Cantilever Honeycomb Sandwich Plate
}

\author{
Junhua Zhang $\mathbb{D}^{1},{ }^{1}$ Xiaodong Yang $\mathbb{D},^{2}$ and Wei Zhang $\mathbb{D}^{2}$ \\ ${ }^{1}$ College of Mechanical Engineering, Beijing Information Science and Technology University, Beijing 100192, China \\ ${ }^{2}$ College of Mechanical Engineering, Beijing University of Technology, Beijing 100124, China
}

Correspondence should be addressed to Junhua Zhang; zjhuar@163.com

Received 11 July 2017; Accepted 22 November 2017; Published 6 March 2018

Academic Editor: Michael J. Schütze

Copyright ( $\odot 2018$ Junhua Zhang et al. This is an open access article distributed under the Creative Commons Attribution License, which permits unrestricted use, distribution, and reproduction in any medium, provided the original work is properly cited.

Dynamics of a cantilever honeycomb sandwich plate are studied in this paper. The governing equations of the composite plate subjected to both in-plane and transverse excitations are derived by using Hamilton's principle and Reddy's third-order shear deformation theory. Based on the Rayleigh-Ritz method, some modes of natural frequencies for the cantilever honeycomb sandwich plate are obtained. The relations between the natural frequencies and the parameters of the plate are investigated. Further, the Galerkin method is used to transform the nonlinear partial differential equations into a set of nonlinear ordinary differential equations. Nonlinear dynamic responses of the cantilever honeycomb sandwich plate to such external and parametric excitations are discussed by using the numerical method. The results show that in-plane and transverse excitations have an important influence on nonlinear dynamic characteristics. Rich dynamics, such as periodic, multiperiodic, quasiperiodic, and chaotic motions, are located and studied by the bifurcation diagram for some specific parameters.

\section{Introduction}

Honeycomb sandwich structures are used widely in aerospace field, vehicles, ships, transport packaging, building decorations, and so on. Honeycomb sandwich structures have many advantages such as light weight, high specific stiffness, and high specific strength, as well as good structural stability and energy absorption [1]. Therefore, many research works have focused on the honeycomb sandwich plates and shells and corresponding dynamic characters with different techniques. Meo et al. [2] studied the response of honeycomb sandwich panels on low-velocity impact damage by using experimental investigation and numerical simulation. The finite element method is one of the useful methods to study dynamics of composite sandwich panels with honeycomb core [3]. Free vibrations of symmetric rectangular honeycomb sandwich panels with simply supported boundaries at the four edges were investigated by using the homotopy analysis method [4]. The analytical model of composite sandwich panels with honeycomb core subjected to high-velocity impact had been developed by Feli and Namdari Pour [5]. Buckling analysis of rectangular plate with hexagonal honeycomb core under combined axial compression and transverse shear loads is given in the reference [6]. The impact behavior of honeycomb sandwich panels has been investigated by finite element method by Menna et al. [7]. The vibration-based spatial damage identification of the honeycomb-core sandwich composite plates was given by using wavelet analysis method [8]. The dynamic behavior of a viscoelastic sandwich composite plate with honeycomb core subjected to the nonuniform blast load was investigated by both theoretical and experimental methods (see the details in Balkan and Mecitoglu [9]). The vibroacoustic bending properties of honeycomb sandwich panels with composite faces were studied by Laurent [10]. The stretch and bending of honeycomb sandwich plates were obtained with skin and height effects by using analytic homogenization method [11].

The abovementioned references mainly used numerical methods or experiments to study the mechanical properties or impact damage, and so on of the honeycomb sandwich structures. In this study, we focus on the case that the cantilever honeycomb sandwich plate is loaded by the joint external and parametric excitations. Free vibrations and nonlinear dynamics for the cantilever honeycomb sandwich plate are given. 


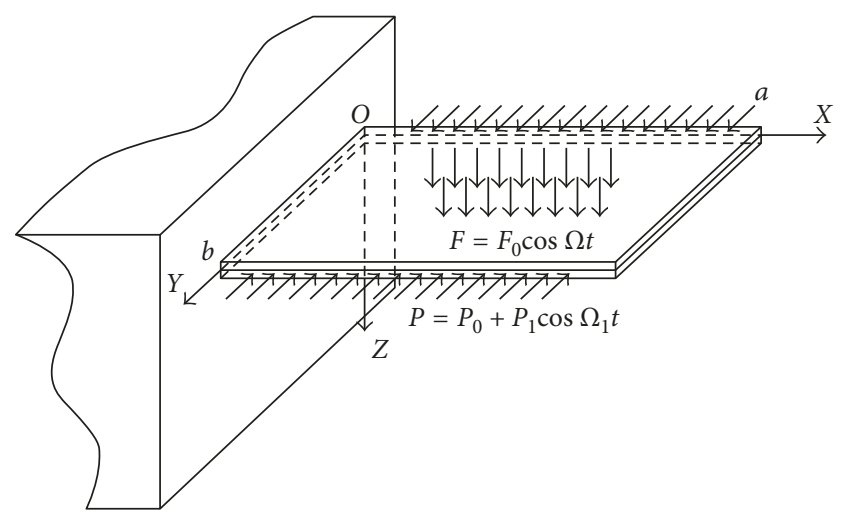

Figure 1: The model of cantilever honeycomb sandwich plate.

This paper is organized as follows. In Section 2, based on Hamilton's principle and Reddy's third-order shear deformation theory, the formulas for the honeycomb sandwich plate subjected to in-plane and transverse excitations are derived. Free transversal vibrations of the plate at cantilever boundary conditions are given by using Rayleigh-Ritz method in Section 3. The variations of natural frequencies with varied parameters of the honeycomb plate are obtained. In Section 4, the formulas for the honeycomb sandwich plate subjected to in-plane and transverse excitations are transformed to ordinary differential equations by using the Galerkin method. The mode functions are selected under cantilever boundary conditions. Numerical simulations are derived to obtain nonlinear response of the honeycomb plate. Finally, conclusions are given.

\section{Equations of Motion for the Plate}

Consider a cantilever honeycomb sandwich plate subjected to both in-plane and transversal excitations, the model and the coordinate system are shown in Figure 1. The plate is of length $a$, width $b$, and thickness $h$. Let $(u, v, w)$ and $\left(u_{0}, v_{0}, w_{0}\right)$ be, respectively, the displacements of an arbitrary point and a point in the middle plane of the plate in the $x, y$, and $z$ directions. The mid-plane rotations of a transverse normal about the $x$ and $y$ axes are denoted by $\phi_{x}$ and $\phi_{y}$, respectively. The plate is subjected to an in-plane excitation $p=p_{0}+$ $p_{1} \cos \Omega_{1} t$ and a transverse excitation $F(x, y) \cos \Omega t$, where $\Omega_{1}$ and $\Omega$ are the excitation frequencies of the transverse and in-plane excitations, respectively.

Based on Reddy's third-order shear deformation theory in Reddy [12], the displacement components of the honeycomb sandwich plate can be represented as follows:

$$
\begin{aligned}
& u(x, y, z, t)=u_{0}(x, y, t)+z \phi_{x}(x, y, t)-\frac{4}{3 h^{2}} z^{3}\left(\phi_{x}+\frac{\partial w_{0}}{\partial x}\right), \\
& v(x, y, z, t)=v_{0}(x, y, t)+z \phi_{y}(x, y, t)-\frac{4}{3 h^{2}} z^{3}\left(\phi_{y}+\frac{\partial w_{0}}{\partial y}\right),
\end{aligned}
$$$$
w(x, y, z, t)=w_{0}(x, y, t) .
$$

where $u_{0}=u(x, y, 0, t), v_{0}=v(x, y, 0, t), w_{0}=w(x, y, 0, t)$, $\phi_{x}=(\partial u / \partial z)_{z=0}$, and $\phi_{y}=(\partial v / \partial z)_{z=0}$.

The relations between strains and displacements according to von Karman nonlinear strains-displacements are given by

$$
\begin{aligned}
& \varepsilon_{x x}=\frac{\partial u}{\partial x}+\frac{1}{2}\left(\frac{\partial w}{\partial x}\right)^{2}, \\
& \varepsilon_{x z}=\frac{1}{2}\left(\frac{\partial u}{\partial z}+\frac{\partial w}{\partial x}\right), \\
& \varepsilon_{x y}=\frac{1}{2}\left(\frac{\partial u}{\partial y}+\frac{\partial v}{\partial x}+\frac{\partial w}{\partial x} \frac{\partial w}{\partial y}\right), \\
& \gamma_{y y}=\frac{\partial v}{\partial y}+\frac{1}{2}\left(\frac{\partial w}{\partial y}\right)^{2}, \\
& \gamma_{y z}=\frac{1}{2}\left(\frac{\partial v}{\partial z}+\frac{\partial w}{\partial y}\right), \\
& \gamma_{z z}=\frac{\partial w}{\partial z} .
\end{aligned}
$$

The constitutive relations of the honeycomb sandwich plate can be written as follows:

$$
\begin{aligned}
\left(\begin{array}{c}
\sigma_{x x} \\
\sigma_{y y} \\
\sigma_{x y}
\end{array}\right)=\left(\begin{array}{ccc}
Q_{11} & Q_{12} & 0 \\
Q_{12} & Q_{22} & 0 \\
0 & 0 & Q_{66}
\end{array}\right)\left(\begin{array}{l}
\varepsilon_{x x} \\
\varepsilon_{y y} \\
\gamma_{x y}
\end{array}\right), \\
\left(\begin{array}{c}
\sigma_{y z} \\
\sigma_{x z}
\end{array}\right)=\left(\begin{array}{cc}
Q_{44} & 0 \\
0 & Q_{55}
\end{array}\right)\left(\begin{array}{l}
\gamma_{y z} \\
\gamma_{x z}
\end{array}\right),
\end{aligned}
$$

where $Q_{11}, Q_{12}, Q_{22}, Q_{44}, Q_{55}$, and $Q_{66}$ are elastic constants which can be written as

$$
\begin{aligned}
& Q_{11}=\frac{E_{x}}{1-v_{x} v_{y}} \\
& Q_{12}=\frac{v_{x} E_{y}}{1-v_{x} v_{y}}, \\
& Q_{22}=\frac{E_{y}}{1-v_{x} v_{y}} . \\
& Q_{44}=G_{y z}, \\
& Q_{55}=G_{x z}, \\
& Q_{66}=G_{x y} .
\end{aligned}
$$

The terms $E_{x}$ and $E_{y}$ are equivalent elastic modulus of the honeycomb core at $x$ and $y$ directions, respectively, and $v_{x}$ and $v_{y}$ are equivalent Poisson's ratios. These equivalent elastic parameters of the honeycomb core can be given by the following equations, and the details can be found in the study of Fu et al. [13]: 


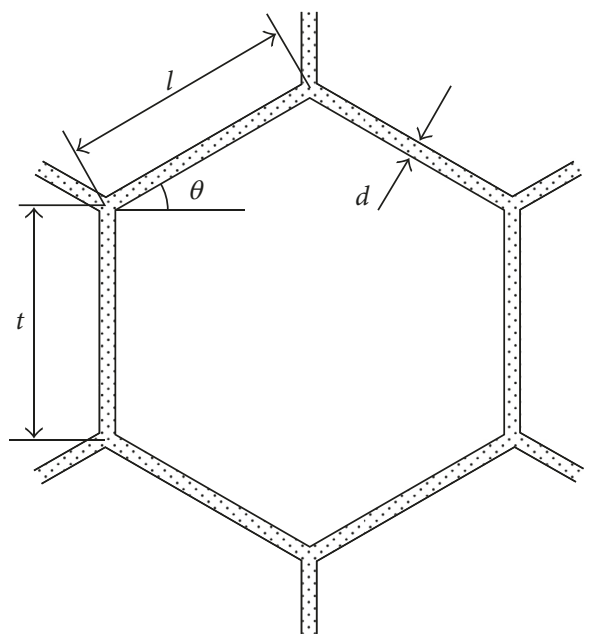

Figure 2: The unit cell of general hexagonal core layer.

$E_{x}=E_{s} \frac{d^{3}}{l^{3}} \frac{\cos \theta+d / l}{(t / l+\sin \theta) \sin ^{2} \theta\left[1+\left(2.4+1.5 v_{s}+\cot ^{2} \theta\right) d^{2} / l^{2}\right]}$ $v_{x}=\frac{\cos \theta(\cos \theta+d / l)\left[1+\left(1.4+1.5 v_{s}\right) d^{2} / l^{2}\right]}{(t / l+\sin \theta) \sin \theta\left[1+\left(2.4+1.5 v_{s}+\cot ^{2} \theta\right) d^{2} / l^{2}\right]}$,

$E_{y}=E_{s} \frac{d^{3}}{l^{3}} \frac{t / l+\sin \theta}{\cos ^{2} \theta(\cos \theta+d / l)}$

$\times \frac{1}{\left[1+\left(2.4+1.5 v_{s}+\tan ^{2} \theta+2(t / l) \sec ^{2} \theta\right) d^{2} / l^{2}\right]}$,

$v_{y}=\frac{(t / l+\sin \theta) \sin \theta}{\cos \theta(\cos \theta+d / l)}$

$\times \frac{\left[1+\left(1.4+1.5 v_{s}\right) d^{2} / l^{2}\right]}{\left[1+\left(2.4+1.5 v_{s}+\tan ^{2} \theta+2(t / l) \sec ^{2} \theta\right) d^{2} / l^{2}\right]}$,

where $d$ is the thickness of the honeycomb core cellular cells and $t$ and $l$ are length of the straight and sloping wall of the honeycomb core cellular cells (Figure 2). $E_{s}$ and $v_{s}$ are, respectively, Young's modulus and Poisson's ratio of the materials for the honeycomb core.

In (4), $G_{x z}$ and $G_{y z}$ are transverse shear moduli, which can be computed by using the following formula:

$$
G=\frac{E}{2(1+v)} \text {. }
$$

The relation between the equivalent density of the honeycomb core $\rho_{c}$ and the density of the materials $\rho_{s}$ is

$$
\frac{\rho_{c}}{\rho_{s}}=\frac{d / l(t / l+2)}{2 \cos \theta(t / l+\sin \theta)} .
$$

The formula above for hexagon honeycomb core can be simplified as

$$
\frac{\rho_{c}}{\rho_{s}}=\frac{2}{\sqrt{3}} \frac{d}{l}
$$

Substituting (2) and (3) into the potential and kinetic functions, the equations of motion for the honeycomb sandwich plate are derived by using Hamilton's principle:

$$
\begin{aligned}
& \frac{\partial N_{x x}}{\partial x}+\frac{\partial N_{x y}}{\partial y}=I_{0} \ddot{u}_{0}+\left(I_{1}-c_{1} I_{3}\right) \ddot{\phi}_{x}-c_{1} I_{3} \frac{\partial \ddot{w}_{0}}{\partial x}, \\
& \frac{\partial N_{x y}}{\partial x}+\frac{\partial N_{y y}}{\partial y}=I_{0} \ddot{v}_{0}+\left(I_{1}-c_{1} I_{3}\right) \ddot{\phi}_{y}-c_{1} I_{3} \frac{\partial \ddot{w}_{0}}{\partial y},
\end{aligned}
$$

$$
\begin{aligned}
& \frac{\partial N_{x x}}{\partial x} \frac{\partial w_{0}}{\partial x}+N_{x x} \frac{\partial^{2} w_{0}}{\partial x^{2}}+\frac{\partial N_{x y}}{\partial x} \frac{\partial w_{0}}{\partial y}+2 N_{x y} \frac{\partial^{2} w_{0}}{\partial x \partial y} \\
& +\frac{\partial N_{x y}}{\partial y} \frac{\partial w_{0}}{\partial x}+\frac{\partial N_{y y}}{\partial y} \frac{\partial w_{0}}{\partial y}+N_{y y} \frac{\partial^{2} w_{0}}{\partial y^{2}} \\
& +\left(\frac{\partial Q_{x}}{\partial x}-c_{2} \frac{\partial R_{x}}{\partial x}\right)+\left(\frac{\partial Q_{y}}{\partial y}-c_{2} \frac{\partial R_{y}}{\partial y}\right) \\
& +c_{1}\left(\frac{\partial^{2} P_{x x}}{\partial x^{2}}+2 \frac{\partial^{2} P_{x y}}{\partial x \partial y}+\frac{\partial^{2} P_{y y}}{\partial y^{2}}\right)+F_{0} \cos \Omega t-\gamma \dot{w}_{0} \\
& =I_{0} \ddot{w}_{0}-c_{1}^{2} I_{6}\left(\frac{\partial^{2} \ddot{w}_{0}}{\partial x^{2}}+\frac{\partial^{2} \ddot{w}_{0}}{\partial y^{2}}\right)+c_{1} I_{3}\left(\frac{\partial \ddot{u}_{0}}{\partial x}+\frac{\partial \ddot{v}_{0}}{\partial y}\right) \\
& +c_{1}\left(I_{4}-c_{1} I_{6}\right)\left(\frac{\partial \ddot{\phi}_{x}}{\partial x}+\frac{\partial \ddot{\phi}_{y}}{\partial y}\right),
\end{aligned}
$$

$$
\begin{aligned}
& \frac{\partial M_{x x}}{\partial x}+\frac{\partial M_{x y}}{\partial y}-c_{1} \frac{\partial P_{x x}}{\partial x}-c_{1} \frac{\partial P_{x y}}{\partial y}-\left(Q_{x}-c_{2} R_{x}\right) \\
& \quad=\left(I_{1}-c_{1} I_{3}\right) \ddot{u}_{0}+\left(I_{2}-2 c_{1} I_{4}+c_{1}^{2} I_{6}\right) \ddot{\phi}_{x}-c_{1}\left(I_{4}-c_{1} I_{6}\right) \frac{\partial \ddot{w}_{0}}{\partial x},
\end{aligned}
$$$$
\frac{\partial M_{x y}}{\partial x}+\frac{\partial M_{y y}}{\partial y}-c_{1} \frac{\partial P_{x y}}{\partial y}-c_{1} \frac{\partial P_{y y}}{\partial y}-\left(Q_{y}-c_{2} R_{y}\right)
$$$$
=\left(I_{1}-c_{1} I_{3}\right) \ddot{v}_{0}+\left(I_{2}-2 c_{1} I_{4}+c_{1}^{2} I_{6}\right) \ddot{\phi}_{y}-c_{1}\left(I_{4}-c_{1} I_{6}\right) \frac{\partial \ddot{w}_{0}}{\partial y},
$$ 
where

$$
\begin{aligned}
& \left(\begin{array}{c}
N_{x x} \\
N_{y y} \\
N_{x y}
\end{array}\right)=\left(\begin{array}{ccc}
A_{11} & A_{12} & 0 \\
A_{12} & A_{22} & 0 \\
0 & 0 & A_{66}
\end{array}\right)\left(\begin{array}{c}
\frac{\partial u_{0}}{\partial x}+\frac{1}{2}\left(\frac{\partial w_{0}}{\partial x}\right)^{2} \\
\frac{\partial v_{0}}{\partial y}+\frac{1}{2}\left(\frac{\partial w_{0}}{\partial y}\right)^{2} \\
\frac{\partial u_{0}}{\partial y}+\frac{\partial v_{0}}{\partial x}+\frac{\partial w_{0}}{\partial x} \frac{\partial w_{0}}{\partial y}
\end{array}\right) \\
& \left(\begin{array}{c}
M_{x x} \\
M_{y y} \\
M_{x y}
\end{array}\right)=\left(\begin{array}{ccc}
D_{11} & D_{12} & 0 \\
D_{21} & D_{22} & 0 \\
0 & 0 & D_{66}
\end{array}\right)\left(\begin{array}{c}
\frac{\partial \phi_{x}}{\partial x} \\
\frac{\partial \phi_{y}}{\partial y} \\
\frac{\partial \phi_{x}}{\partial y}+\frac{\partial \phi_{y}}{\partial x}
\end{array}\right) \\
& -c_{1}\left(\begin{array}{ccc}
F_{11} & F_{12} & 0 \\
F_{21} & F_{22} & 0 \\
0 & 0 & F_{66}
\end{array}\right)\left(\begin{array}{c}
\frac{\partial \phi_{x}}{\partial x}+\frac{\partial^{2} w_{0}}{\partial x^{2}} \\
\frac{\partial \phi_{y}}{\partial y}+\frac{\partial^{2} w_{0}}{\partial y^{2}} \\
\frac{\partial \phi_{x}}{\partial y}+\frac{\partial \phi_{y}}{\partial x}+2 \frac{\partial^{2} w_{0}}{\partial x \partial y}
\end{array}\right) \\
& \left(\begin{array}{c}
P_{x x} \\
P_{y y} \\
P_{x y}
\end{array}\right)=\left(\begin{array}{ccc}
F_{11} & F_{12} & 0 \\
F_{21} & F_{22} & 0 \\
0 & 0 & F_{66}
\end{array}\right)\left(\begin{array}{c}
\frac{\partial \phi_{x}}{\partial x} \\
\frac{\partial \phi_{y}}{\partial y} \\
\frac{\partial \phi_{x}}{\partial y}+\frac{\partial \phi_{y}}{\partial x}
\end{array}\right) \\
& -c_{1}\left(\begin{array}{ccc}
H_{11} & H_{12} & 0 \\
H_{21} & H_{22} & 0 \\
0 & 0 & H_{66}
\end{array}\right)\left(\begin{array}{c}
\frac{\partial \phi_{x}}{\partial x}+\frac{\partial^{2} w_{0}}{\partial x^{2}} \\
\frac{\partial \phi_{y}}{\partial y}+\frac{\partial^{2} w_{0}}{\partial y^{2}} \\
\frac{\partial \phi_{x}}{\partial y}+\frac{\partial \phi_{y}}{\partial x}+2 \frac{\partial^{2} w_{0}}{\partial x \partial y}
\end{array}\right), \\
& \left(\begin{array}{c}
Q_{x} \\
Q_{y}
\end{array}\right)=\left(\begin{array}{cc}
A_{44} & 0 \\
0 & A_{55}
\end{array}\right)\left(\begin{array}{c}
\phi_{y}+\frac{\partial w_{0}}{\partial y} \\
\phi_{x}+\frac{\partial w_{0}}{\partial x}
\end{array}\right) \\
& -c_{2}\left(\begin{array}{cc}
D_{44} & 0 \\
0 & D_{55}
\end{array}\right)\left(\begin{array}{c}
\phi_{y}+\frac{\partial w_{0}}{\partial y} \\
\phi_{x}+\frac{\partial w_{0}}{\partial x}
\end{array}\right),
\end{aligned}
$$

$$
\begin{gathered}
\left(\begin{array}{l}
R_{x} \\
R_{y}
\end{array}\right)=\left(\begin{array}{cc}
D_{44} & 0 \\
0 & D_{55}
\end{array}\right)\left(\begin{array}{c}
\phi_{y}+\frac{\partial w_{0}}{\partial y} \\
\phi_{x}+\frac{\partial w_{0}}{\partial x}
\end{array}\right) \\
-c_{2}\left(\begin{array}{cc}
F_{44} & 0 \\
0 & F_{55}
\end{array}\right)\left(\begin{array}{l}
\phi_{y}+\frac{\partial w_{0}}{\partial y} \\
\phi_{x}+\frac{\partial w_{0}}{\partial x}
\end{array}\right)
\end{gathered}
$$

The stiffness elements of the honeycomb sandwich plate are given by

$$
\begin{aligned}
\left(A_{i j}, B_{i j}, D_{i j}, E_{i j}, F_{i j}, H_{i j}\right)= & \int_{-h / 2}^{h / 2} Q_{i j}\left(1, z, z^{2}, z^{3}, z^{4}, z^{6}\right) d z, \\
& (i, j=1,2,6), \\
\left(A_{i j}, D_{i j}, F_{i j}\right)= & \int_{-h / 2}^{h / 2} Q_{i j}\left(1, z, z^{2}, z^{4}\right) d z, \\
& (i, j=4,5) .
\end{aligned}
$$

\section{Frequencies of Transverse Vibrations}

In this section, the frequencies of transverse vibration for $w$ direction are considered by using the Rayleigh-Ritz method. The deflections for $w$ is as follows:

$$
w(x, y, t)=W(x, y) \sin \omega t .
$$

The kinetic energy of the honeycomb sandwich plate is

$$
T=\frac{1}{2} \iint m\left(\frac{\partial w}{\partial t}\right)^{2} d x d y
$$

The maximum kinetic energy is of the following form:

$$
T_{\max }=\frac{\omega^{2}}{2} \iint m W^{2} d x d y .
$$

The potential energy of the honeycomb plate is of the following form:

$$
\begin{aligned}
U_{\max }= & \frac{1}{2} \iiint\left(\sigma_{x x} \varepsilon_{x x}+\sigma_{y y} \varepsilon_{y y}+\sigma_{x y} \gamma_{x y}+\sigma_{y z} \gamma_{y z}\right. \\
& \left.+\sigma_{x z} \gamma_{x z}\right) d V .
\end{aligned}
$$

The stresses and strains in (15) are obtained from (2) and (3).

The boundary conditions for the cantilever honeycomb sandwich plate are given as follows: 


$$
\begin{aligned}
& x=0: w=v=u=\phi_{x}=\phi_{y}=0, \\
& x=a: N_{x y}=M_{x x}=M_{x y}-c_{1} P_{x y}=\bar{Q}_{x}=0, \\
& y=0: N_{y y}=N_{x y}=M_{y y}=M_{x y}-c_{1} P_{x y}=\bar{Q}_{y}=0, \\
& y=b: N_{y y}=N_{x y}=M_{y y}=M_{x y}-c_{1} P_{x y}=\bar{Q}_{y}=0, \\
& \int_{0}^{a} N_{x x \mid x=0, a} d y=\int_{0}^{a}\left(p_{0}+p_{1} \cos \Omega_{1} t\right) d y,
\end{aligned}
$$

where the equivalent shear forces are

$$
\begin{gathered}
\bar{Q}_{x}=Q_{x}+\frac{\partial M_{x y}}{\partial y}-c_{2} R_{x}+c_{1}\left(\frac{\partial P_{x x}}{\partial x}+\frac{\partial P_{x y}}{\partial y}\right), \\
\bar{Q}_{y}=Q_{y}+\frac{\partial M_{x y}}{\partial x}-c_{2} R_{y}+c_{1}\left(\frac{\partial P_{y y}}{\partial y}+\frac{\partial P_{x y}}{\partial y}\right) .
\end{gathered}
$$
form:

The mode function $w_{0}$ can be written as the following

$$
w_{0}=C_{11} X_{1} Y_{1}+C_{12} X_{1} Y_{2}+C_{21} X_{2} Y_{1}+C_{22} X_{2} Y_{2},
$$

where $C_{11}, C_{12}, C_{21}$, and $C_{22}$ are modal parameters and

$$
\begin{aligned}
& X_{1}=\sin \left(\lambda_{1} x\right)-\sinh \left(\lambda_{1} x\right)+\alpha_{1}\left(\cosh \left(\lambda_{1} x\right)-\cos \left(\lambda_{1} x\right)\right) \\
& X_{2}=\sin \left(\lambda_{2} x\right)-\sinh \left(\lambda_{2} x\right)+\alpha_{2}\left(\cosh \left(\lambda_{2} x\right)-\cos \left(\lambda_{2} x\right)\right) \\
& Y_{1}=1 \\
& Y_{2}=\sqrt{3}\left(\frac{2 y}{b}-1\right)
\end{aligned}
$$

where

$$
\begin{gathered}
\cos \lambda_{i} a \cosh \left(\lambda_{i} a\right)+1=0, \quad i=1,2, \\
\alpha_{1}=\frac{\sinh \left(\lambda_{1} a\right)+\sin \left(\lambda_{1} a\right)}{\cosh \left(\lambda_{1} a\right)+\cos \left(\lambda_{1} a\right)} \\
\alpha_{2}=\frac{\sinh \left(\lambda_{2} a\right)+\sin \left(\lambda_{2} a\right)}{\cosh \left(\lambda_{2} a\right)+\cos \left(\lambda_{2} a\right)} .
\end{gathered}
$$

The mode functions (19) satisfy the cantilever boundary conditions (16). Since the honeycomb plate system is a conservative system during free vibrations, the maximum kinetic energy is equal to the maximum potential energy. According to the Rayleigh-Ritz method, compute the Jacobian matrix

$$
\begin{array}{r}
{\left[\frac{\partial\left(T_{\max }-U_{\max }\right)}{\partial C_{11}}, \frac{\partial\left(T_{\max }-U_{\max }\right)}{\partial C_{12}}, \frac{\partial\left(T_{\max }-U_{\max }\right)}{\partial C_{21}},\right.} \\
\left.\frac{\partial\left(T_{\max }-U_{\max }\right)}{\partial C_{22}}\right],
\end{array}
$$

and let the determinant equal to 0 ; the first four frequencies for the honeycomb sandwich plate can be obtained numerically.

The parameters of the honeycomb sandwich plate are as follows: density $\rho_{s}=2.66 \times 10^{3} \mathrm{~kg} / \mathrm{m}^{3}$, Young's modulus $E_{s}=72 \times 10^{9} \mathrm{~Pa}$, Poisson's ratio $v=0.33$, the length $a=5 \mathrm{~m}$ and width $b=2 \mathrm{~m}$, the thickness of the core is $h_{c}=0.01 \mathrm{~m}$, and the length of the straight and sloping wall of the honeycomb core cellular cells $d=0.0008 \mathrm{~m}$ and $l=0.01 \mathrm{~m}$. Table 1 lists the first four orders of natural frequencies of the cantilever honeycomb sandwich plate with the changes of the honeycomb core thickness. From the data in Table 1, we can see that the natural frequency of the first four orders of the honeycomb sandwich panel increases slowly with the increase of the thickness of the honeycomb cores.

Table 2 shows the variation of the natural frequencies of the honeycomb sandwich panel with the density of the material of the honeycomb core under cantilever boundary conditions. From the data in Table 2, it can be concluded that the natural frequency of the honeycomb sandwich panel decreases with the increase of the density of the matrix material.

Table 3 shows the effect of the change in the wall length of the honeycomb cell of the honeycomb sandwich panel on the natural frequency of the first four bands of the honeycomb sandwich panel. From the data in Table 3, we can find that, with the increase of the cell length of the honeycomb core, the natural frequencies of the first four bands of the honeycomb sandwich panel showed a slight increase.

Table 4 shows the effect of the variation of the wall thickness of the honeycomb unit on the natural frequencies of the honeycomb sandwich panel. From the data in Table 4, it can be seen that, with the increase of the wall thickness of the honeycomb cell, the first four natural frequencies of the honeycomb sandwich panel show a decreasing tendency.

It can be concluded from Tables 1-4 that the thickness of the honeycomb core and the density of the materials have little effect on the natural frequencies. The frequencies increase with increase of cell length of the honeycomb core and with decrease of the wall thickness of the honeycomb core.

In this section, the influence of the honeycomb core size and the material density on the natural frequencies of the plate are given, which provides some guidance for the application of honeycomb plate in engineering to avoid resonance. In next section, nonlinear dynamics of the cantilever honeycomb sandwich plate jointed external and parametric excitations are studied.

\section{Nonlinear Responses of the Plate}

In this section, the 2-truncated function for $w_{0}$ is assumed as the following:

$$
w_{0}=w_{1}(t) X_{1}(x) Y_{3}(y)+w_{2}(t) X_{2}(x) Y_{3}(y)
$$

where

$$
\begin{aligned}
Y_{3}(x)= & \sin \mu_{3} y+\sinh \mu_{3} y \\
& -\beta_{3}\left(\cosh \mu_{3} x+\cos \mu_{3} x\right),
\end{aligned}
$$

$\cos \mu_{3} b \cosh \mu_{3} b-1=0$

$$
\beta_{3}=\frac{\sinh \mu_{3} b-\sin \mu_{3} b}{\cosh \mu_{3} b-\cos \mu_{3} b} .
$$

Truncated functions for other directions are 
TABle 1: Frequencies of different core layer thicknesses of honeycomb sandwich plate.

\begin{tabular}{|c|c|c|c|c|c|}
\hline \multirow{2}{*}{ Modal } & \multicolumn{5}{|c|}{$h_{c}(\mathrm{~m})$} \\
\hline & 0.01 & 0.02 & 0.03 & 0.04 & 0.05 \\
\hline 1 & 360.28803 & 360.28803 & 360.28805 & 360.28807 & 360.28809 \\
\hline 2 & 1243.29964 & 1243.29970 & 1243.29979 & 1243.29992 & 1243.30009 \\
\hline 3 & 2207.55777 & 2207.55929 & 2207.56181 & 2207.56540 & 2207.56995 \\
\hline 4 & 2507.85212 & 2507.86810 & 2507.89476 & 2507.93202 & 2507.97997 \\
\hline
\end{tabular}

TABle 2: Frequencies of different material densities of honeycomb sandwich plate.

\begin{tabular}{lccccc}
\hline Modal & \multicolumn{3}{c}{$\rho_{s}\left(10^{3} \mathrm{~kg} / \mathrm{m}^{3}\right)$} & 2.69 & 357.70 \\
\hline 1 & 2.66 & 2.67 & 359.61270 & 358.94115 & 358.27335 \\
2 & 360.28803 & 1240.96918 & 1238.65177 & 1236.34730 & 1234.05564 \\
3 & 1243.29964 & 2203.41989 & 2199.30518 & 2195.21344 & 2191.14447 \\
4 & 2207.55777 & 2503.15136 & 2498.47694 & 2493.82861 & 2489.20612 \\
\hline
\end{tabular}

TABLe 3: Frequencies of different lengths of the unit cell.

\begin{tabular}{lccccc}
\hline Modal & & & $l(\mathrm{~m})$ & & 0.011 \\
& 0.008 & 0.009 & 0.010 & 377.87327 & 0.012 \\
\hline 1 & 322.25141 & 341.79923 & 360.28803 & 1303.98366 & 1361.96651 \\
3 & 1112.04101 & 1179.49760 & 1243.29964 & 2315.30612 & 2418.25837 \\
4 & 1974.49969 & 2094.27319 & 2207.55777 & 2630.25750 & 2747.21435 \\
\hline
\end{tabular}

TAвLE 4: Frequencies of different thicknesses of the unit cell.

\begin{tabular}{lccccc}
\hline Modal & & $t(\mathrm{~m})$ & 0.0008 & 3.0009 \\
\hline 1 & 0.0005 & 0.0006 & 0.0007 & 380.28803 & 339.68281 \\
2 & 455.73231 & 416.02478 & 1329.14322 & 1243.29964 & 1172.19414 \\
3 & 1572.66346 & 1435.63876 & 2359.97852 & 2207.55777 & 2081.30542 \\
4 & 2792.36425 & 2549.06814 & 2681.00668 & 2507.85212 & 2364.42566 \\
\hline
\end{tabular}

$$
\begin{aligned}
& u_{0}=u_{1}(t) \frac{\partial X_{1}(x)}{\partial x} Y_{3}(y)+u_{2}(t) \frac{\partial X_{2}(x)}{\partial x} Y_{3}(y), \\
& v_{0}=v_{1}(t) X_{1}(x) \frac{\partial Y_{3}(y)}{\partial y}+v_{2}(t) X_{2}(x) \frac{\partial Y_{3}(y)}{\partial y}, \\
& \phi_{x}=\phi_{x 1}(t) \frac{\partial X_{1}(x)}{\partial x} Y_{3}(y)+\phi_{x 2}(t) \frac{\partial X_{2}(x)}{\partial x} Y_{3}(y), \\
& \phi_{y}=\phi_{y 1}(t) X_{1}(x) \frac{\partial Y_{3}(y)}{\partial y}+\phi_{y 2}(t) X_{2}(x) \frac{\partial Y_{3}(y)}{\partial y} .
\end{aligned}
$$

Hence, the displacements have been transferred into the generalized coordinates, and the truncated functions satisfy the cantilever boundary conditions (16). Similarly, the transversal force is also truncated into the generalized coordinates:

$$
F_{0}(t)=F_{1}(t) X_{1}(x) Y_{3}(y)+F_{2}(t) X_{2}(x) Y_{3}(y) .
$$

Substituting the mode functions (22), (24), (25) into (9), neglecting the inertia terms for in-plane and rotary since they are small compared with that of transverse, one can obtain the nonlinear ordinary differential equations as follows:

$$
\begin{aligned}
\ddot{w}_{1} & +f_{17} \gamma \dot{w}_{1}+f_{15} w_{1}+f_{16} w_{2}+f_{19} w_{1}\left(P_{0}+P_{1} \cos \Omega_{1} t\right) \\
& +f_{11} w_{1}^{3}+f_{12} w_{1}^{2} w_{2}+f_{13} w_{1} w_{2}^{2}+f_{14} w_{2}^{3}=f_{18} F_{1} \cos \Omega t, \\
\ddot{w}_{2} & +f_{27} \gamma \dot{w}_{2}+f_{25} w_{1}+f_{26} w_{2}+f_{29} w_{2}\left(P_{0}+P_{1} \cos \Omega_{1} t\right) \\
& +f_{21} w_{1}^{3}+f_{22} w_{1}^{2} w_{2}+f_{23} w_{1} w_{2}^{2}+f_{24} w_{2}^{3}=f_{28} F_{2} \cos \Omega t .
\end{aligned}
$$

Equations (26) are typical nonlinear equations governing the vibrations of generalized coordinates undergoing 


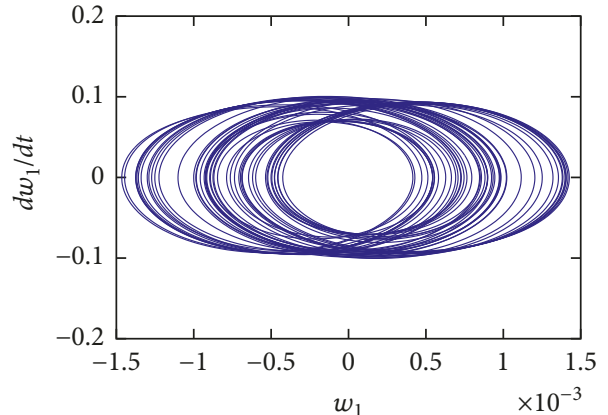

(a)

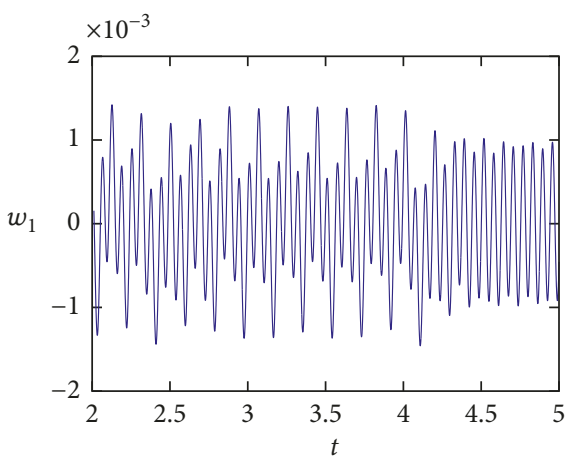

(c)

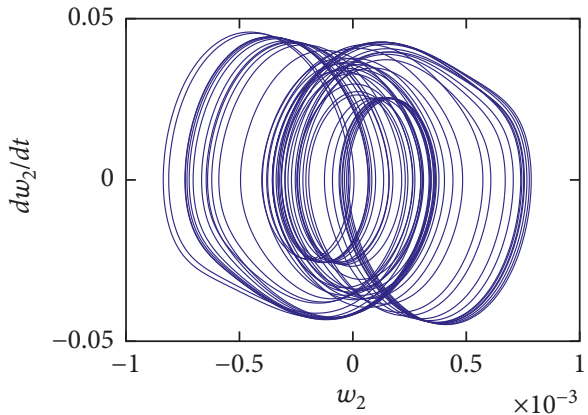

(b)

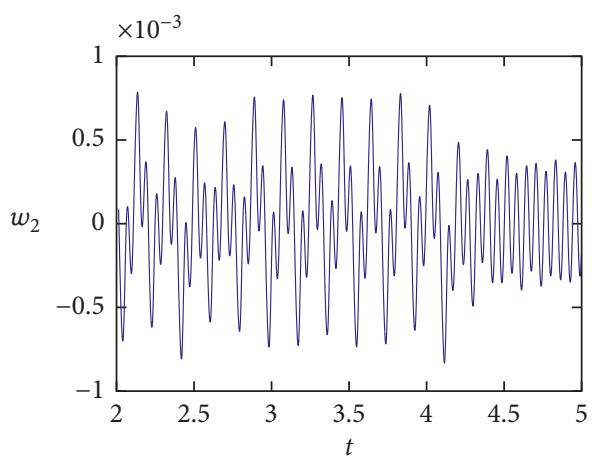

(d)

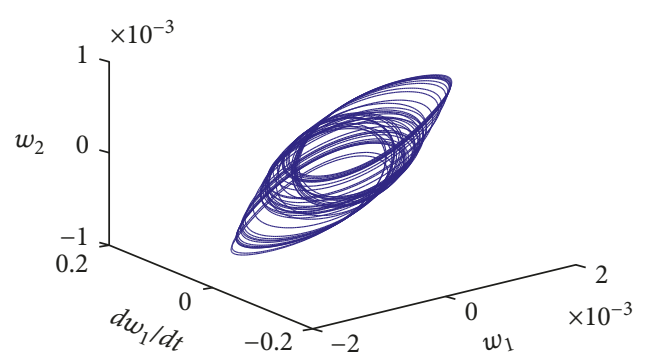

(e)

Figure 3: Chaotic motion of the cantilever honeycomb sandwich plate.

external excitation with frequency $\Omega$ and parametric excitation with frequency $\Omega_{1}$.

Next, numerical simulations are given to study the nonlinear responses of the honeycomb sandwich plate under transverse and in-plane loads of (26). It is assumed that the plate is made of aluminum, and the physical and geometric parameters are the same as that of Section 3. Other parameters, that is, the in-plane force and the transverse excitation, are chosen as follows: $\Omega=\Omega_{1}=$ $100 \mathrm{~Hz}, \gamma=150 \mathrm{~N} \cdot \mathrm{s} / \mathrm{m}$. The loads are chosen as $F_{1}=$ $25 \mathrm{~Pa}, F_{2}=10 \mathrm{~Pa}$ and $P_{0}=25 \mathrm{~Pa}, P_{1}=24.9 \mathrm{~Pa}$. Figure 3 illustrates chaotic motions for the honeycomb sandwich plate. Figures 3(a) and 3(b) present the phase portraits on the planes $\left(w_{1}, \dot{w}_{1}\right)$ and $\left(w_{2}, \dot{w}_{2}\right)$. Figures $3(\mathrm{c})$ and $3(\mathrm{~d})$ give the time histories on the planes $\left(t, w_{1}\right)$ and $\left(t, w_{2}\right)$.
Figure 3(e) represents the phase portraits in threedimensional space $\left(w_{1}, \dot{w}_{1}, w_{2}\right)$.

Chosen the transverse loads as $F_{1}=5 \mathrm{~Pa}$ and $F_{2}=7 \mathrm{~Pa}$ and the in-plane load $P_{0}=80 \mathrm{~Pa}$, Figure 4 presents the bifurcations of the honeycomb plate with variations of parametric excitation amplitude $P_{1}$. From the bifurcation diagram, it can be seen that the honeycomb sandwich plate can have periodic and multiperiodic motions when parametric amplitude $P_{1}$ changes. It is periodic doubling bifurcation when the in-plane force $P_{1}$ is about $200 \mathrm{~Pa}$.

Figure 5 shows periodic motions when the in-plane load $P_{1}=-260 \mathrm{~Pa}$.

When the in-plane $P_{1}$ increases, multiperiodic motions are found for the honeycomb sandwich plate. Figure 6 represents 2-periodic motions as $P_{1}=1300 \mathrm{~Pa}$. 


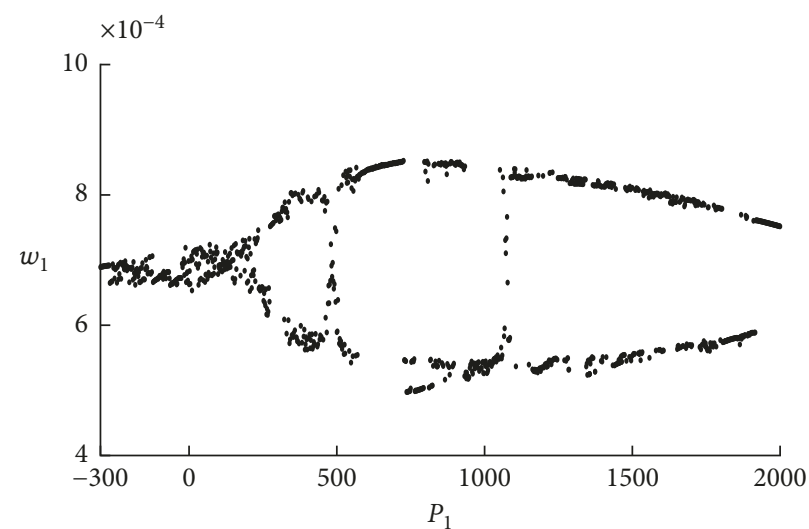

Figure 4: The bifurcation diagram of the system with change of $P_{1}$.

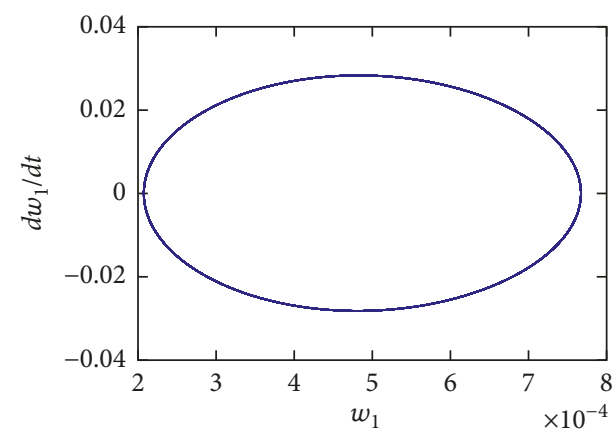

(a)

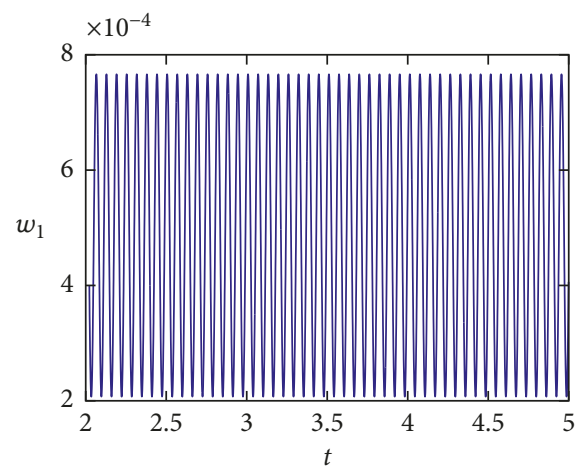

(c)

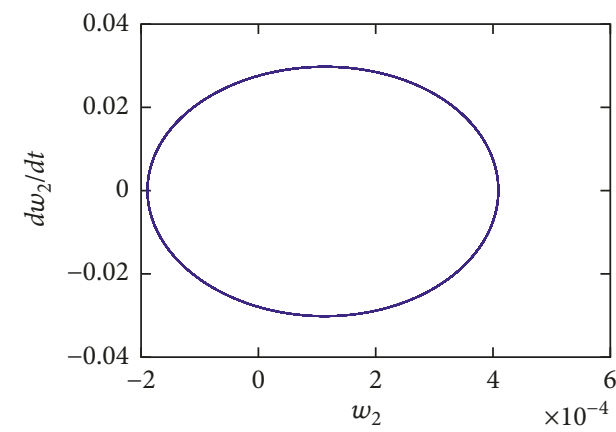

(b)

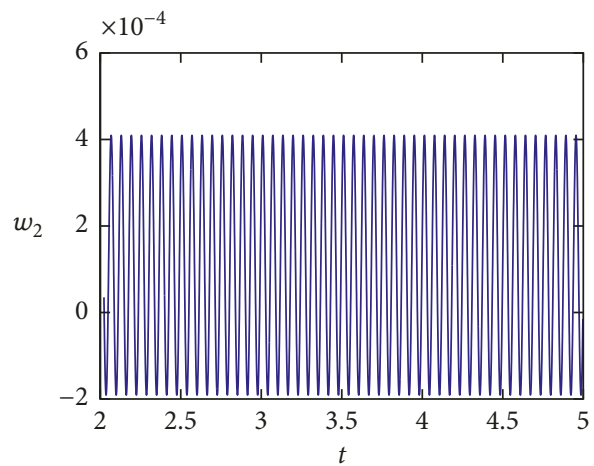

(d)

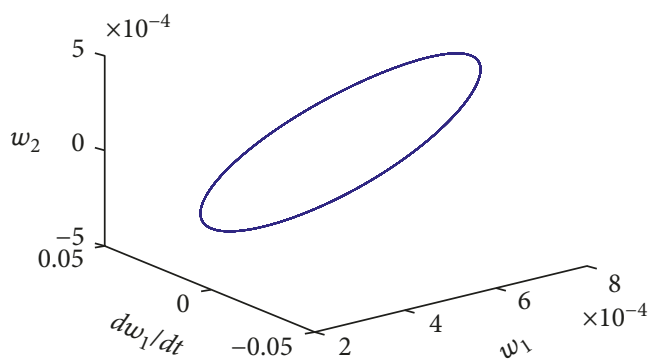

(e)

FIgURE 5: Periodic motions of the cantilever honeycomb sandwich plate. 


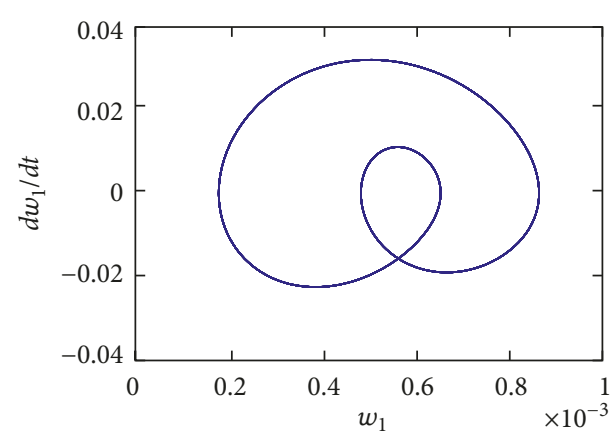

(a)

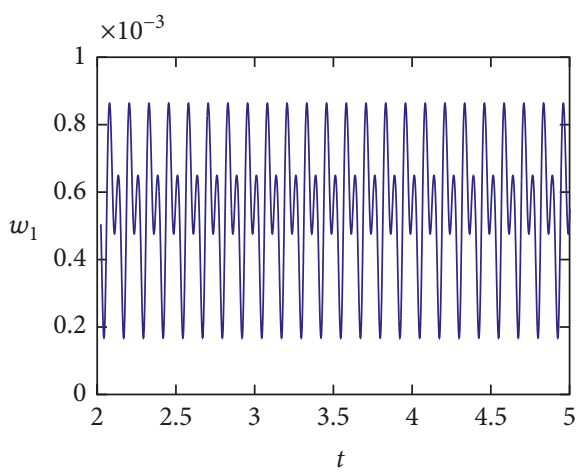

(c)

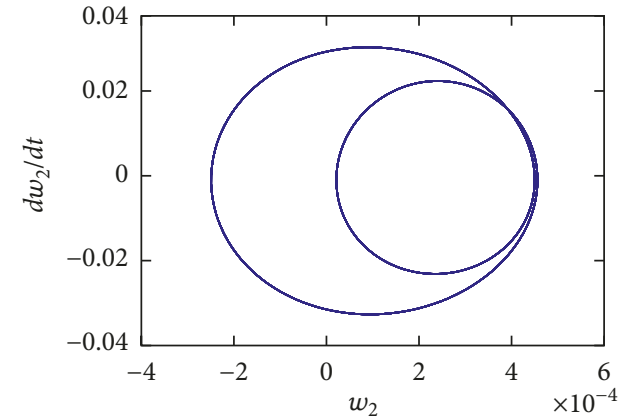

(b)

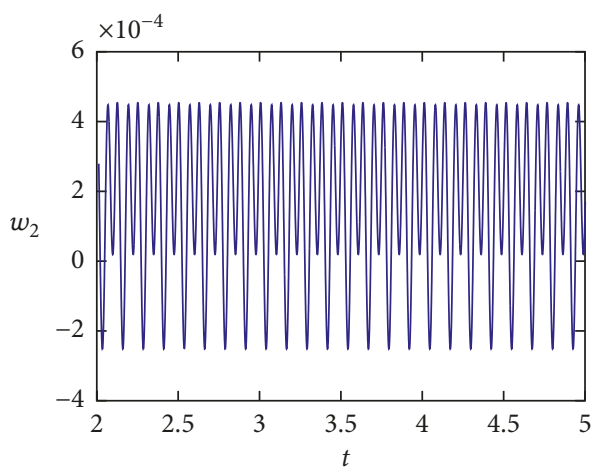

(d)

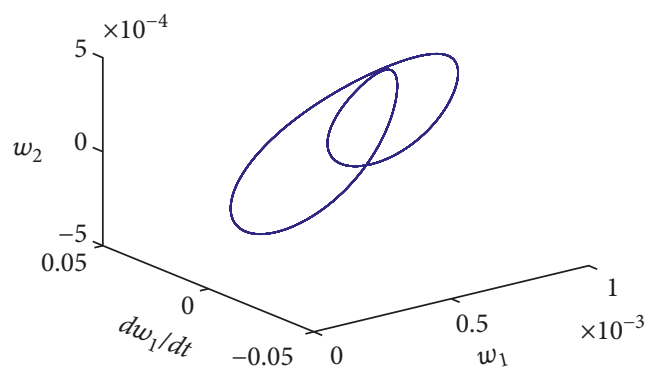

(e)

Figure 6: Period-2 motion of the cantilever honeycomb sandwich plate.

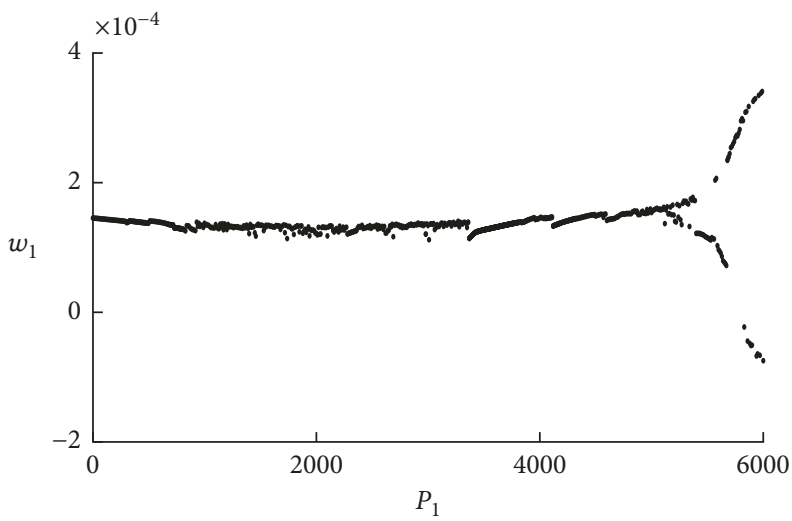

Figure 7: The bifurcation diagram of the system with change of $P_{1}$. 


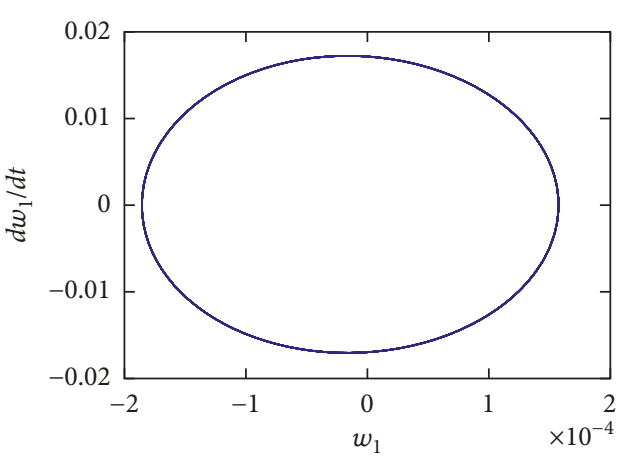

(a)

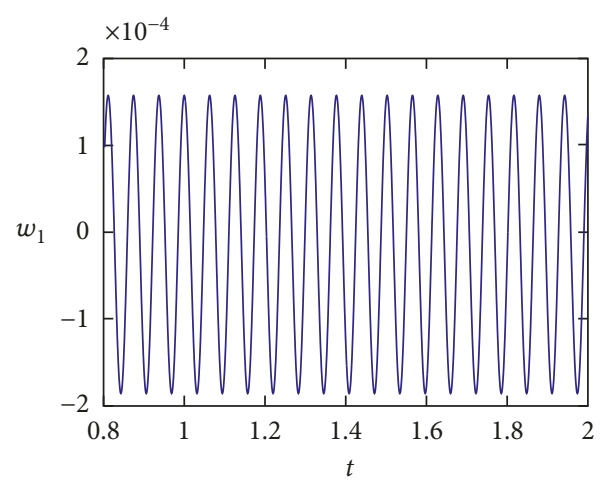

(c)

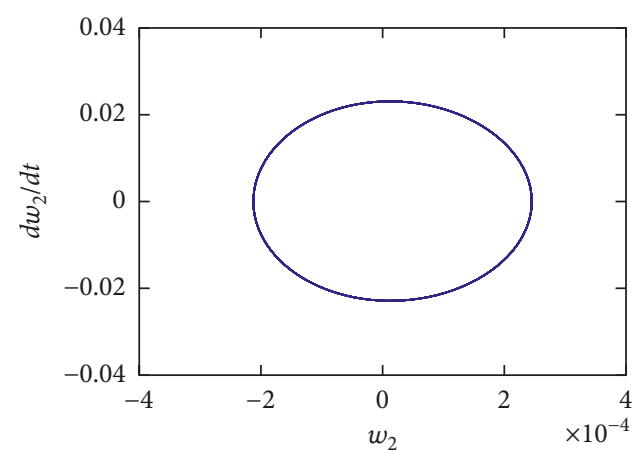

(b)

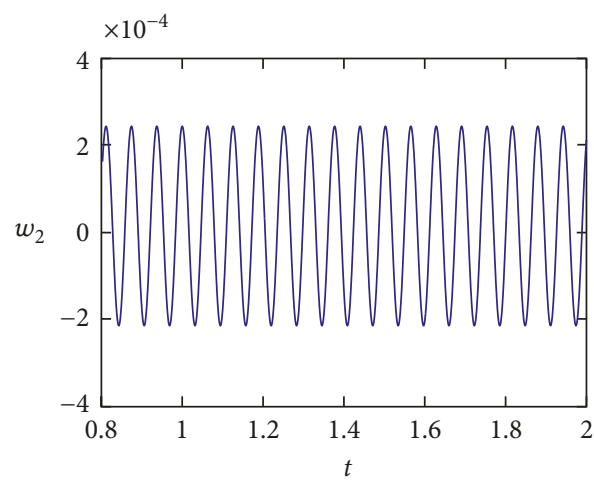

(d)

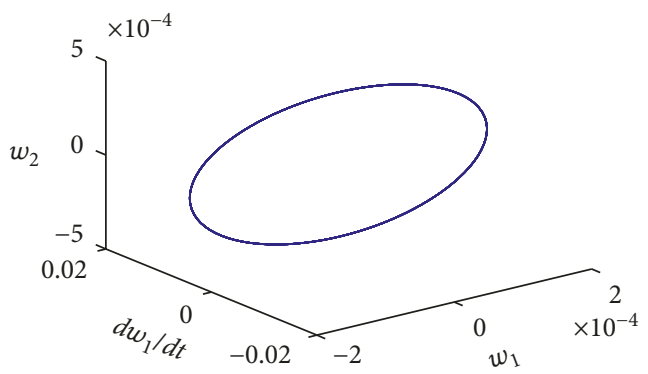

(e)

Figure 8: Periodic motion of the cantilever honeycomb sandwich plate.

When the thickness of the honeycomb core cells changes to $0.0012 \mathrm{~m}$ and other parameters are kept the same, the bifurcation diagram with in-plane force changing has been presented in Figure 7. It can be seen from the bifurcation diagram that it is periodic doubling bifurcation when the in-plane force $P_{1}$ is about $5000 \mathrm{~Pa}$. Compared with bifurcation diagram (Figure 4), the bifurcation point moves to the right; that is, with the increase of the thickness of the honeycomb core, the force $P_{1}$ needs increase to bifurcate. In addition, if the force $P_{1}$ is larger than $6000 \mathrm{~Pa}$, the amplitude of the plate increases obviously and then divergences.

When $P_{1}=1000 \mathrm{~Pa}$, Figure 8 shows periodic motion of the honeycomb sandwich plate.
When the force $P_{1}$ is chosen as $P_{1}=5500 \mathrm{~Pa}$, the multiperiodic motions are obtained as shown in Figure 9.

\section{Conclusions}

Dynamics of a cantilever honeycomb sandwich plate subjected to both in-plane and transverse excitations have been studied. The governing equations are derived by using Hamilton's principle and Reddy's third-order shear deformation theory. The natural frequencies of the cantilever honeycomb sandwich plate are obtained by Rayleigh-Ritz method. Then, the Galerkin truncation procedure is employed to transform the nonlinear partial differential equations into a set of nonlinear ordinary 


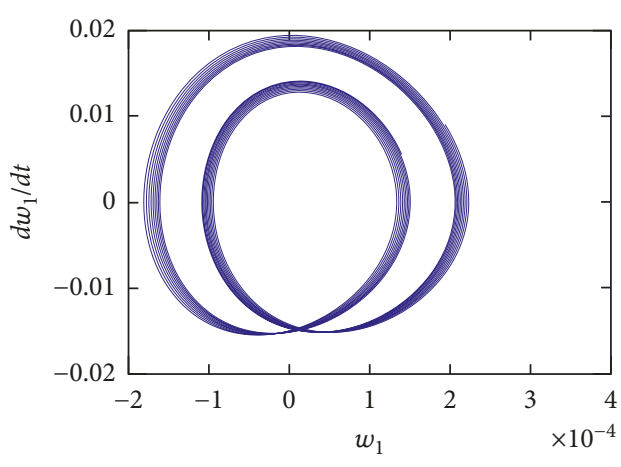

(a)

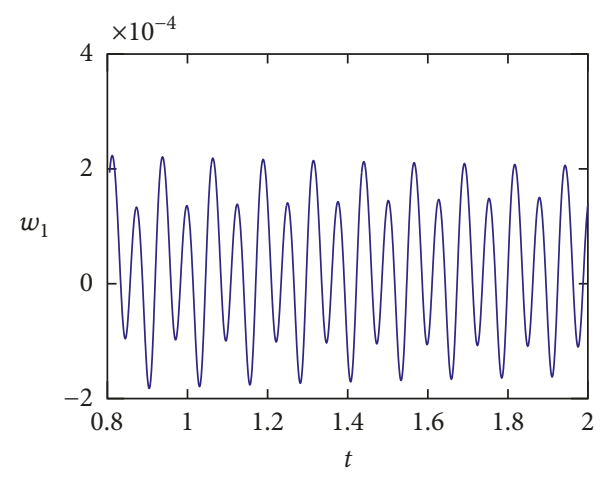

(c)

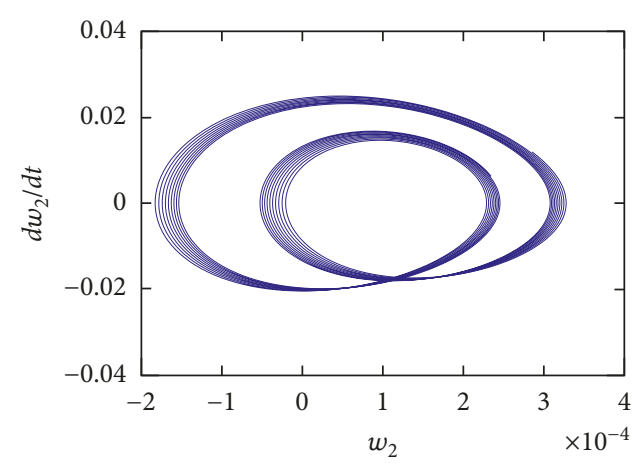

(b)

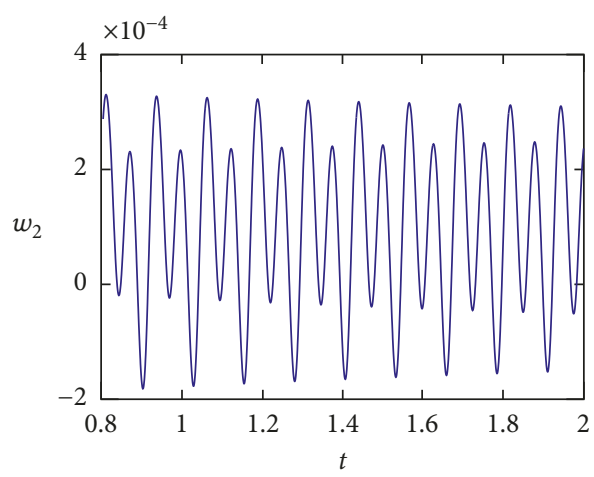

(d)

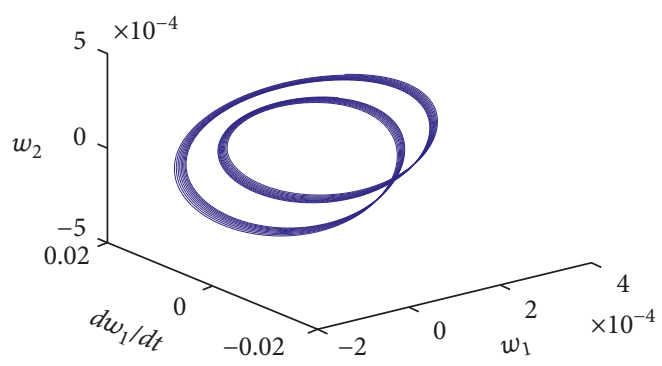

(e)

FIGURE 9: Multiperiodic motions of the cantilever honeycomb sandwich plate.

differential equations. Nonlinear dynamic responses of the cantilever honeycomb sandwich plate to such external and parametric excitations are studied using numerical method. From numerical simulations, it can be concluded that there exist chaotic motions as well as periodic and multiperiodic motions in the cantilever honeycomb sandwich plate subjected to the transversal and in-plane excitations.

\section{Conflicts of Interest}

The authors declare that there are no conflicts of interest regarding the publication of this paper.

\section{Authors' Contributions}

All the authors contributed equally to this work. Junhua Zhang and Wei Zhang conceived and designed the project. Junhua Zhang did the theoretical deduction and analyzed the results. Xiaodong Yang performed the numerical simulations. Junhua Zhang and Xiaodong Yang wrote the manuscript. Wei Zhang provided useful suggestions to this work.

\section{Acknowledgments}

The authors gratefully acknowledge the support of the National Natural Science Foundation of China (11472057, 
11732005), the Qinxin Talents Cultivation Program of Beijing Information Science and Technology University (QXTCP B201701), and the Science and Technology Project of Beijing Municipal Education Commission (KM201711232002).

\section{References}

[1] L. J. Gibson and M. F. Ashby, Cellular Solids: Structure and Properties, Cambridge University Press, Cambridge, UK, 2nd edition, 1997.

[2] M. Meo, R. Vignjevic, and G. Marengo, "The response of honeycomb sandwich panels under low-velocity impact loading," International Journal of Mechanical Sciences, vol. 47, no. 9, pp. 1301-1325, 2005.

[3] B. L. Buitrago, C. Santiuste, S. Sánchez-Sáez, E. Barbero, and C. Navarro, "Modelling of composite sandwich structures with honeycomb core subjected to high-velocity impact," Composite Structures, vol. 92, no. 9, pp. 2090-2096, 2010.

[4] Y. Q. Li, F. Li, and D. W. Zhu, "Geometrically nonlinear free vibrations of the symmetric rectangular honeycomb sandwich panels with simply supported boundaries," Composite Structures, vol. 92, no. 5, pp. 1110-1119, 2010.

[5] S. Feli and M. H. Namdari Pour, "An analytical model for composite sandwich panels with honeycomb core subjected to high-velocity impact," Composites Part B: Engineering, vol. 43, no. 5, pp. 2439-2447, 2012.

[6] F. López Jiménez and N. Triantafyllidis, "Buckling of rectangular and hexagonal honeycomb under combined axial compression and transverse shear," International Journal of Solids and Structures, vol. 50, no. 24, pp. 3934-3946, 2013.

[7] C. Menna, A. Zinno, D. Asprone, and A. Prota, "Numerical assessment of the impact behavior of honeycomb sandwich structures," Composite Structures, vol. 106, pp. 326-339, 2013.

[8] A. Katunin, "Vibration-based spatial damage identification in honeycomb-core sandwich composite structures using wavelet analysis," Composite Structures, vol. 118, pp. 385-391, 2014.

[9] D. Balkan and Z. Mecitoglu, "Nonlinear dynamic behavior of viscoelastic sandwich composite plates under non-uniform blast load: theory and experiment," International Journal of Impact Engineering, vol. 72, pp. 85-104, 2014.

[10] G. Laurent, "Vibroacoustic flexural properties of symmetric honeycomb sandwich panels with composite faces," Journal of Sound and Vibration, vol. 343, pp. 71-103, 2015.

[11] Y. M. Li, M. P. Hoang, B. Abbes, F. Abbes, and Y. Q. Guo, "Analytical homogenization for stretch and bending of honeycomb sandwich plates with skin and height effects," Composite Structures, vol. 120, pp. 406-416, 2015.

[12] J. N. Reddy, Mechanics of Laminated Composite Plates and Shells: Theory and Analysis, CRC Press, New York, USA, 2004.

[13] M. Fu, O. Xu, and Y. Chen, "An overview of equivalent parameters of honeycomb core," Materials Review, vol. 29, no. 3, pp. 127-134, 2015. 


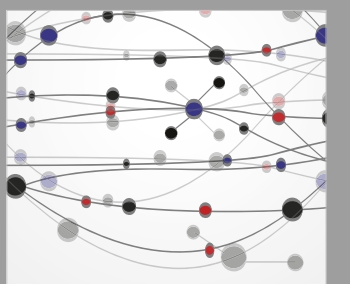

The Scientific World Journal
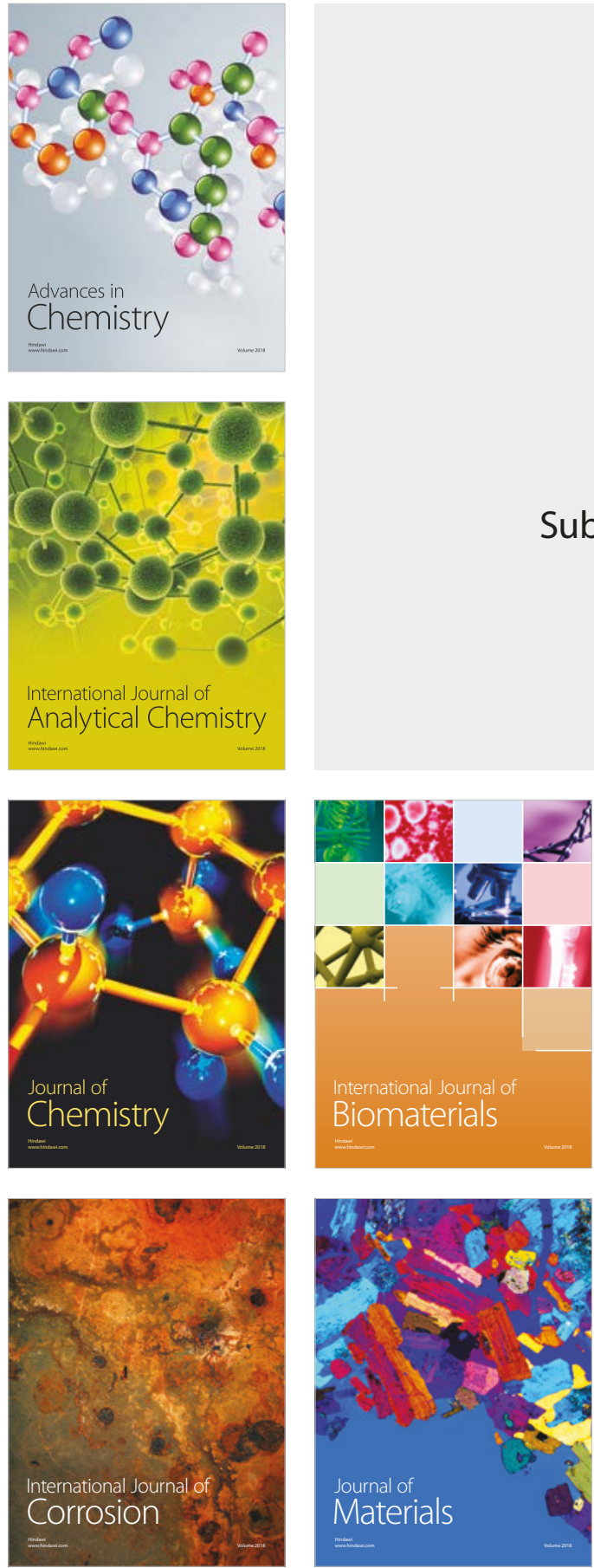

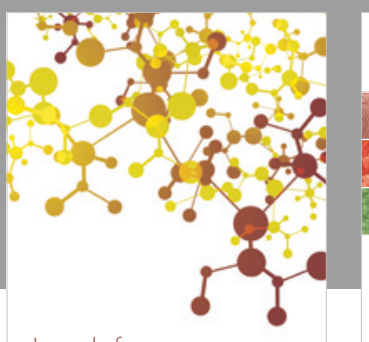

Journal of

Applied Chemistry
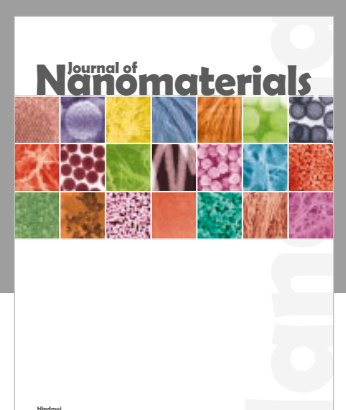

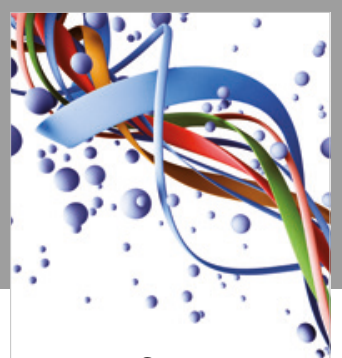

Scientifica

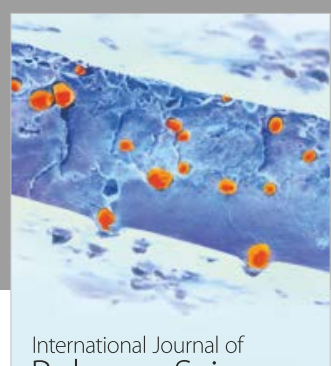

Polymer Science

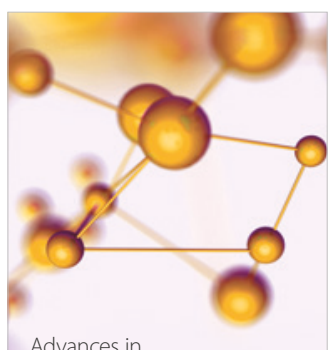

Physical Chemistry
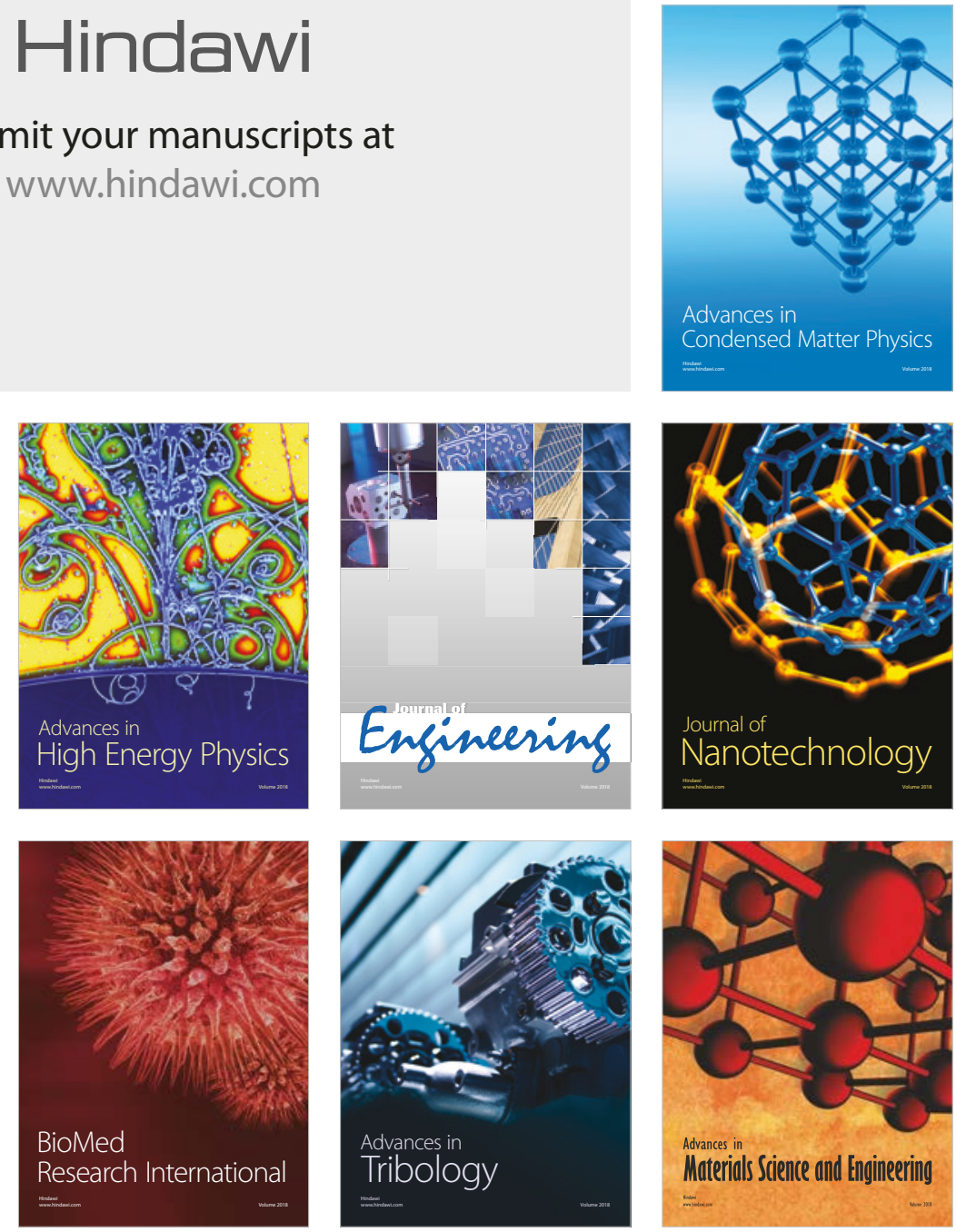